\title{
Prospects of Creating Memorable Experience in Nepalese Tourism and Hospitality Industry
}

\author{
Chanakya P. Rijal* \\ Sudip Ghimire**
}

\begin{abstract}
This paper contributes to explore the concept of experience economy theory of Pine and Gilmore (1998) as a basis for measuring the prospects of creating memorable experience in Nepalese tourism and hospitality industry identifying the key elements of Nepalese tourism and hospitality industry and its dimension based on the four realms of experience as proposed by the author of experience economy theory. For assessing this result, an ethnographic study based on semi-structured interview were conducted with leading professional of Nepalese tourism and hospitality field and also with a visitor. The result of the study has clearly depicted and further elaborated the Nepalese key elements of tourism and hospitality experience, present status, major attributes, underlying anticipation of the industry, illustrating the implication while focused on the various core elements and the indigenous attributes of Nepalese tourism and hospitality industry. However, the results are confined only with the prospects based on the confirmation of the scope in experience economy for this industry with very little focus on the prospects for designing further experience or staging the experience. It has also served as a basis for understanding the emergent theory in experiential consumption of tourism and hospitality services in Nepalese sector that can be applied to the varying stage of development in the promotion and marketing of tourism and hospitality service offering. Consequently, it has also offered a new theoretical direction for tourism and hospitality policy makers, planners as well as a practical insight for the contemporary application of the findings for marketers and decision makers.
\end{abstract}

Keywords: Experience economy, realms of experience, ethnographic dialectics, experience staging.

\footnotetext{
* Dr. Chanakya P. Rijal holds a phD degree in leadership and has been working as an Adjunct faculty of Research and Behavioral Sciences at Nepal Academy of Tourism and Hotel Management (NATHM), Kathmandu, Nepal. Email: rijalcpr@gmail.com

** Sudip Ghimire holds a Master Degree in Hospitality Management from NATHM, Tribhuvan University, Nepal. This article is an outcome of his master's thesis report. Email: sudip_ghimire2003@yahoo.com
} 


\section{Introduction}

The pioneer contribution through invention of experience economy theory laid foundation for the valid recognition from numerous scholars around the globe probing the need and importance for the inclusion of experiential attributes in any product and services in order to make a memorable encounter for the clients with lasting memory (Pine \& Gilmore, 1998). The work on 'experience economy' argues that the economy has shifted from service to experience pattern which is known as the progression of economic value. Thus, there is a transition from selling service to selling experience by means of customizing the commoditized business with an upgraded offering to the next stage of economic value.

In the context of tourism and hospitality sector, it can be altercated that basic practices such as selling travel packages and basic lodging and fooding services alone cannot benefit the tourist and clients as their coveted intention are to experience something new which they have not experienced before and which are also worth enjoyable. For this, the need of involving the customers and actively engaging is proven pivotal for creating memorable experiences.

Major activities of the hospitality operation can be infused to improve guest experiences such as wake-up calls and shuttle-bus service by layering an enjoyable experience atop the existing services by applying a theme to turn a service into an experience, thus uncovering many potential ideas for creating experiences, harmonizing a set of impression for engaging the guest and ultimately improving the guest experience (Gilmore \& Pine, 2002) which can be regarded as the important cause for successfulness of tourism business as today's tourists seek appealing, unique and memorable experience shaped by their motivation, preceding travel experiences (Ellis \& Rossman, 2008). It seems reasonable to expect that tourism and hospitality industries need to move forward in the direction of experience creation by using services as the stage, and goods as props, to engage customers for creating memorable event (Pine \& Gilmore, 1998: 98).

Even before the emergence of the experience economy, tourism industry started being regarded as a leading industry for staging experience as Sternberg (1997: 952, 954) concisely put, “Tourism basically sells a 'staged' experience... tourism's major profitable activity is the formation of the touristic experience." Thus, considering the paramount significance of this industry in Nepal, the prospects of creating experience by means of staging the various inputs of tourism and hospitality seems imperative to signify the potentiality of this industry. Moreover, the entire world of business has been shifting its focus from more traditional, production intensive system to more flexible and memorable service intensive one. Here, promoting this industry as a major business of Nepal could serve instrumental to project Nepal from 
the 'nowhere' position to one of the 'leading' nations in the world of business (Rijal, 2015) in experience economy.

This paper has established and explored a conceptual framework based on the four realms of an experience, i.e., 4Es -- entertainment, esthetic, education and escapism dimension of experience representing a number of elements of Nepalese tourism and hospitality industry, and subsequently, categorizing them according to the type of experience they are capable of creating. Establishing the relationships between 4Es of an experience of the Nepalese tourism and hospitality elements, the prospects of creating memorable experience is tested by linking together with a strand of thoughts from the findings of a recent research.

Of course, the results of this study will contribute to both academia and industry as this study is also the first of its type in the Nepalese context to evaluate the prospect of overall tourism and hospitality industry in experience economy scenario. Therefore, it depicts a new angle from which the entire industry can be regarded. In future, this study also can serve as a guidance in the effective design of memorable experience based researches concerning the overall Nepalese tourism and hospitality attractions. Specifically, this work aimed to explore the prospects and potentiality of Nepalese tourism and hospitality industry for creating meaningful and memorable experience as per the four realms of an experience based on Nepalese core and indigenous elements, investigate the present status and prevailing practices of the industry with respect to the realms of an experiences, major prospects, challenges and solutions for the creation of memorable experiences of indigenous Nepalese origin.

\section{Memorable Experience in Tourism and Hospitality}

The word "experience" is derived from two conjoined Latin words "experientia" and "experiri" meaning "knowledge gained by repeated trails" and "to try, test" respectively (Gelter, 2006). Tourism and hospitality experiences are created through a process of visiting, learning and enjoying activities in an environment away from home especially in hospitality industry (Stramboulis \& Skayannis, 2003). Other scholars have recognized that the experiences are generally internally produced and it is rightly said that the person creates his/her own experience based on his/her backgrounds, values, attitudes and beliefs brought to the situation (Knutson, Beck, Him \& Cha, 2006).

With a significant rise in investment from domestic and international investors in Nepalese tourism and hospitality sector with displayed confidence on the heels of the growing tourist influx and increasing demand for quality hospitality services (Lamba, 2014), identification and promotion of new product and services by bolstering the intangible assets of Nepal emphasizing the people and culture and significantly improving the product and services with new innovation while being 
focused to rebrand Nepal's image, can help to improve quality and tourist experiences (Siddharthinc, 2015) and there arises the need of upgrading the current tourism and hospitality business to focus on providing individually customized hospitality and travel experiences (Erdly \& Kesterson-Townes, 2003) as tourism and hospitality industry over the world is transforming from a product-focused, physical-asset intensive business to a customer-focused, experience-centric (Knutson, 2006) because customers do not buy service delivery; they buy experiences; they do not buy service quality; they buy memories and they do not buy food and drink; they buy meal experiences, revisited Hemmington (2007: 749) on consumer behavior in experience economy.

Along with this basic understanding for the need of creating Memorable Experience in tourism and hospitality sector it is also apparent to understand clearly about what forms the Memorable Experience. In this vein, development of scale in two research papers examining Memorable Experience in Tourism sector are noteworthy. In the words of Kim, Ritchie and McCormick (2012), the hedonism, novelty, local culture, refreshment, meaningfulness, involvement and knowledge are the key construct or factors responsible for creating Memorable Tourism Experience. By extending the concept of Memorable Tourism Experience (Sthapit, 2013) added that adverse feeling' is also the determinant for Memorable Tourism Experience which is however not of positive kind. Another model which emphasizes on the relation between value of products and the experiential consumption in cost of money the tourist pay, can be regarded as a significant development for measuring tourist experience (Tarssanen, 2009: 17-18). Experience Pyramid is the tool created for figuring out the experience content of tourism product which is also the framework for experience production developed by Tarssanen and Kylänen (2006). Use of this pyramid are extensive in the thesis research of two native scenarios (Shrestha, 2014) and (Kafle, 2014) focusing to measure visitor experiences in Ghandruk and Chitwan National Park respectively. The later one had also used the four realm of experience model as in Pine and Gilmore (1998).

Several studies have tried to focus on the experiential aspects of hospitality industry of which (Oh, Fiore \& Jeoung, 2007) research on U.S. based B\&B accommodation industry with an experience model of Pine and Gilmore (1998) concluded that plausible consequences of customer experiences, such as satisfaction, arousal, memory, and overall quality depends heavily on the experiential offering, i.e., education, esthetics, entertainment and escapism. Guests of luxury hotels are not just looking for service quality and its features, for example, staff courtesy, hotel appearances, quality foods, etc. but also attached importance to experiential service attributes in those hotels (Mohsin \& Lockyer, 2010; Cetin \& Dincer, 2014) for gaining positive feedback and loyalty. 
Today's travelers are more experience-focused and to meet these demand preferences, hoteliers are seeking innovative alternatives and due to this, a specialized lodging concept has gained popularity over the last several years in the US, Europe and Asia which is lifestyle membership clubs which offers basic facilities, such as meeting and event spaces, food and beverage outlets, nightclubs, pools, and spas, and they include boutique hotel components with a focus on providing social interaction and workspaces for like-minded individuals, often in niche industries such as fashion, fitness, arts and cinema which primarily aims to produce a creative and local experience (Roth \& Fishbin, 2015).

\section{Conceptual Insights in Experience Economy}

Numerous scholar in the last two decades have sought the significant need of shifting economic progress to new direction inventing the new economic concept, especially suited with the tourism and hospitality industry with depth focus on attention economy, emotion economy, entertainment economy, a dream society or experience economy of which all are interlinked with experiences as a means to differentiate brands of hospitality, tourism destinations and escape from the commoditization trap (Pine \& Gilmore, 1999; Schmitt, 2003; Pullman \& Gross, 2003).

The core philosophy of the experience economy is that customers are in a search of new aspects of products and services which shapes their demands to experience something which also challenges the producers to offer something better- such as added value through additional services or the core product or services (Pine \& Gilmore, 1999; Jensen, 1999; Tarassanen \& Kylanen, 2006). The nature of competition also changes due to such trend on the demand of the clients. Thus, there is a serious concern for client's attention. For example, growing concern of health conscious clients created another market segment in tourism and hospitality industry, the hotels are marketed as design hotels, and meals are served in restaurants by waiters singing opera (vocally trained waiters) to provide unique entertainment to the guest. In Nepal, traditional homes are also acquiring best choices of the tourists for accommodation than others because it gives them a unique experience of the beauty and traditional culture.

The progression of economic value is illustrated in diagrammatic form in left continuum. The left signifies competitive position from a low of undifferentiated to a high of differential. The horizontal continuum on pricing extends from market to premium rates. Figure 1 presents with the detailed portray of various evolutionary stages of economic development. 
Figure 1: The progression of economic value

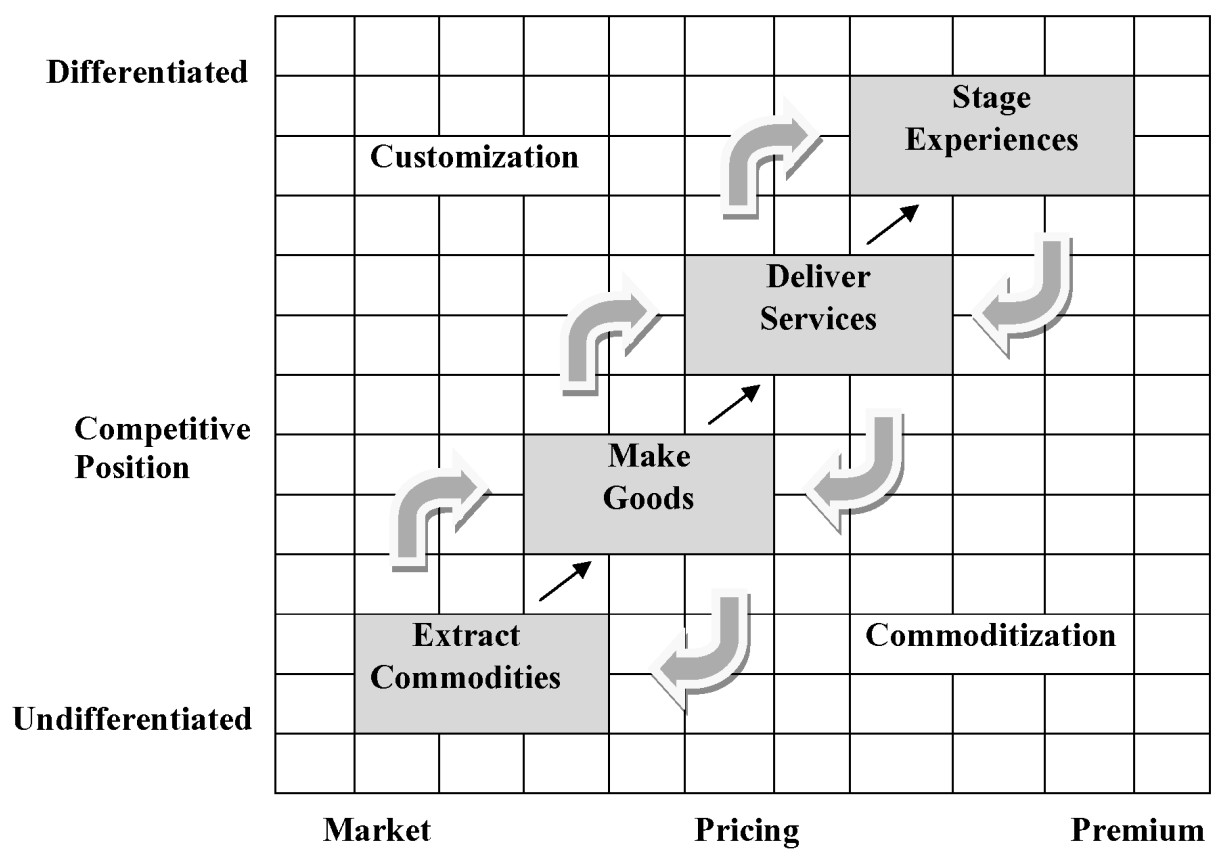

Source: Pine \& Gilmore (1999: 2).

Experiences are a distinct economic offering, as different from services as services are from goods. Pine and Gilmore (1999) differentiated the fundamentals of economic offerings in terms of function, nature, attribute, supply, seller, buyer and demand. Commodities are fungible, goods tangible, services intangible, experiences are memorable.

\section{Four Realms of Experiences}

Pine and Gilmore (1998) have agreed that the experiences exemplify four realms, namely -- education, entertainment, escapism and esthetics that manifest across two continuous dimensions. The figure below illustrates the four main experiential dimensions of Pine and Gilmore (1998). 


\section{Figure 2: The four dimensions of an experience}

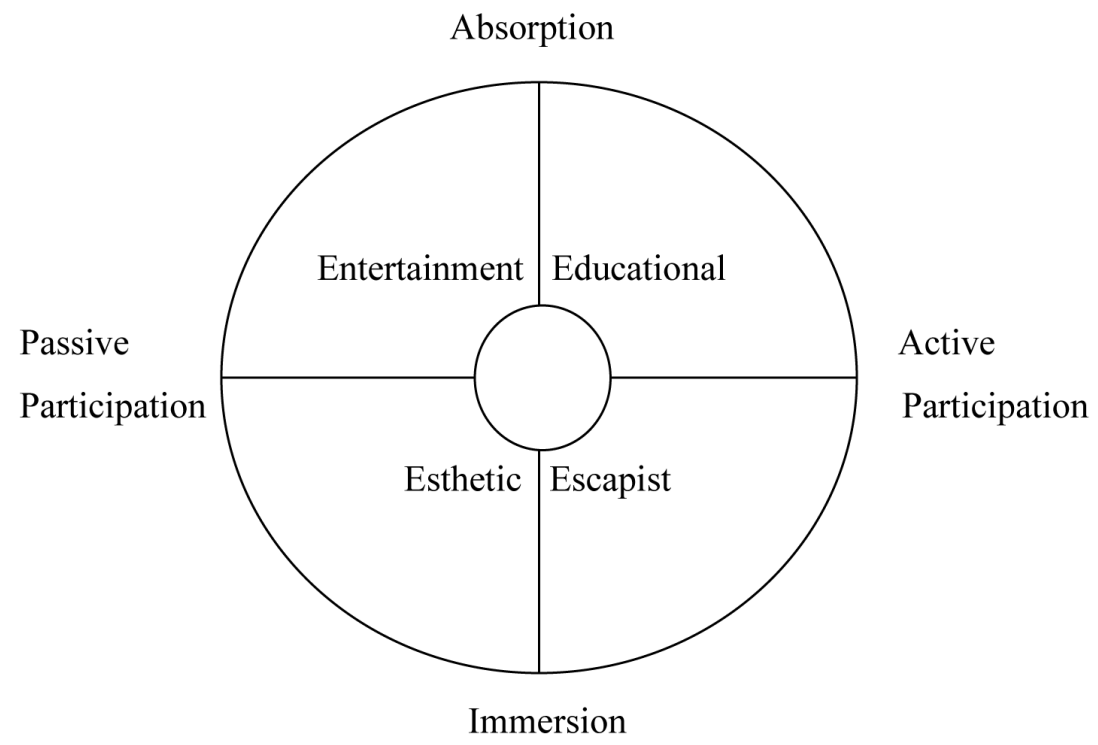

Source: Pine \& Gilmore (1999: 6).

The first dimension indicates either active or passive customer participation. With passive participation, the customers do not affect the performance and have more of a mental presence, such as a virtual tour of a heritage museum. Being active is closely related to seeing the customer as a "prosumer" (Toffler, 1980), that is, one who both consumes and produces the service. In these cases, the production or creation of the experiences will depend on the customer's active participation, such as in rafting and amusement or joining in the cultural dancing performed at the museum.

The second dimension, comprises two extremes - absorption and immersion. Being absorbed in an experience implies being mentally involved in the experience, such as watching a live cultural dance demonstration, while immersion implies being physically involved in the experience, for example, when participating in the cultural dancing. According to Pine and Gilmore (1998), entertaining experiences lean towards customer absorption and passive participation, while educational experiences involve active participation and absorption. Escapist experiences may include a degree of education, but involve greater customer immersion. Esthetic experiences typically result in higher levels of customer immersion but with low levels of customer participation. The richest experiences are those encompassing aspects of all four realms, forming a "sweet spot" around the area where the spectra meet. 


\section{Reflections from Related Studies}

Numerous researchers had already examined the development and application of the four experience realm in tourism and hospitality sector. As mentioned earlier, Oh, Fiore and Jeoung (2007) have examined it in bed-and-breakfast accommodation and concluded that realm of experience not only conceptual fit but also serves as practical measurement framework for the study of tourist experiences. Likewise, Ramesh Raj Kunwar, the Nepalese tourism scholar first applied this theory in the Nepalese context for the study of food tourism (2011: 89-90).

A recent research in cruising tourism has revealed the relationship among cruiser's experiences, satisfaction, and intention to recommend (Hosany \& Witham, 2010). Whereas, Quadri-Felitti and Fiore (2012) have observed that 4Es are equally relevant and useful in conceptualizing the wine tourism experience. Additionally, Mehmetoglu and Engen (2011) research based in music festival and museum has resulted with a thought that different dimensions of experience affect the visitor's level of satisfaction and also finds out that experiences are needed to be created and staged depending on different influences of visitor's satisfaction.

Wang, Feng and Feng (2013) have conducted a research in casino hotels and has revealed that casino hotel tourists with different genders significantly vary in their entertainment experience but not in other type of experience whereas tourists with different ages do not have significant variance in all four categories of experience in casino hotels.

Maria and Loureiro (2014) have attempted to contribute theoretically to understand influence of experience and its influences with place attachment and behavioral intentions through positive emotions and memory in rural tourism context and has proved that esthetic dimension of experience emerges as the most relevant in shaping the overall experience of the visitors.

Other research which have used experience economy realm in tourism and hospitality context are (Radder \& Han, 2015) in museum, (Ali, Hussain \& Ragavan, 2014) in a resort, (Singh-Manhas \& Ramjit, 2013) in chain hotels, (Park, Oh \& Park, 2010) for film festival participant and visitors, (Lo, Qu \& Wetprasit, 2013) in spa tourism, (Manthiou, Lee, Tang \& Chiang, 2014) in festival (as a segment of tourism industry), (Song, Lee, Park, Hwang \& Reisinger, 2014) in temple stay (cultural tourism), (Chang \& Lin, 2015) in creative life industry, (Jurowski, 2009) in tourist destination, (Suntikul \& Jachna, 2015) in heritage site (historic center), (Willard, Frost \& Lade, 2012) in battlefield (dark tourism context) and (Hwand \& Lyu, 2015) in golf tournament tourist as part of sports tourism.

Besides, Hayes and MacLeod (2007), in a research on heritage trails in context of urban cultural tourism, have concluded with the necessity of developing and 
designing trails using experience design principles of Pine and Gilmore (1998) to maximize visitor engagement in a destination.

\section{Conceptual Framework}

Considering the above review and the objectives of present research, the conceptual framework based on the four realm of experience is executed from overall Nepalese tourism and hospitality context subjected for the valid confirmation from the inquiry.

Figure 3: Conceptual framework of the study

\section{Exploration of Four Realms of Experiences}

1. Education: Absorption of knowledge and engaging the intellect -- about learning experiences

2. Esthetic: Passive immersion and special moments to remember -- about being there

3. Escapism: Active immersion, participation and forgetting time -- about doing

4. Entertainment: Passive absorption, seeing and listening -- about sensing

Realms of Tourism and Hospitality Experiences in Nepal

\begin{tabular}{|c|c|c|c|}
\hline Education & Esthetic & Escapism & Entertainment \\
\hline 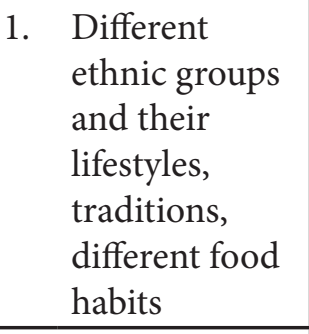 & $\begin{array}{l}\text { 1. Sightseeing } \\
\text { of mountains, } \\
\text { rivers, lakes, } \\
\text { etc. }\end{array}$ & $\begin{array}{l}\text { 1. Trekking, } \\
\text { hiking, } \\
\text { mountaineering } \\
\text { and other } \\
\text { adventurous } \\
\text { tourism } \\
\text { activities }\end{array}$ & $\begin{array}{l}\text { 1. Touring in } \\
\text { traditional } \\
\text { vehicles }\end{array}$ \\
\hline $\begin{array}{l}\text { 2. Rural lifestyles } \\
\text { and activities } \\
\text { such as } \\
\text { traditional } \\
\text { farming. }\end{array}$ & $\begin{array}{l}\text { 2. Nepal's } \\
\text { cultural, } \\
\text { historical } \\
\text { sites and } \\
\text { ethnic } \\
\text { background } \\
\text { and its } \\
\text { uniqueness }\end{array}$ & 2. Safari & $\begin{array}{l}\text { 2. Hospitality } \\
\text { events- } \\
\text { food } \\
\text { festivals, } \\
\text { street } \\
\text { festivals, } \\
\text { music } \\
\text { consortium, } \\
\text { etc. }\end{array}$ \\
\hline
\end{tabular}




\begin{tabular}{|c|c|c|}
\hline $\begin{array}{l}\text { 3. Ethnic } \\
\text { languages, } \\
\text { dresses and } \\
\text { ornaments }\end{array}$ & $\begin{array}{ll}\text { 2. Holy } \\
\text { pilgrimages, } \\
\text { religious } \\
\text { destinations }\end{array}$ & 3. Sports \\
\hline $\begin{array}{l}\text { 4haru-Mithila } \\
\text { art galleries } \\
\text { and other } \\
\text { historical- } \\
\text { cultural } \\
\text { museums } \\
\text { and places, } \\
\text { heritages }\end{array}$ & $\begin{array}{l}\text { 4. National } \\
\text { parks, plants, } \\
\text { birds and } \\
\text { wild habitat }\end{array}$ & \\
\hline $\begin{array}{l}\text { 5. Paintings } \\
\text { related to } \\
\text { historical } \\
\text { myths and } \\
\text { legends }\end{array}$ & & \\
\hline $\begin{array}{l}\text { 6. Nepalese art } \\
\text { and craft, } \\
\text { architecture } \\
\text { and religious } \\
\text { symbols }\end{array}$ & & \\
\hline
\end{tabular}

Source: Pine \& Gilmore(1999: 6).

\section{Educational experiences in tourism and hospitality}

It has been recognized that eating local cuisine helps tourists to gain in-depth knowledge and understanding about a destination's culture, the chance to learn new things and their involvement in cooking contributes to their outstanding experiences (Hjalager \& Richards, 2002; Getz, 2000). On the other hand, Cetin and Bilgihan (2015) have recognized that for tourism, education-based experiences are usually related to engagement with local culture as tourist value almost everything that is a part of the local culture.

Educational experience in the context of rural lifestyle and activities (e.g., participation in theme fairs or learning how to make handicrafts and/or performing agricultural activities) are seen as one of the most dominant factor among the overall rural experience in a research conducted among 250 rural tourists in sixty rural lodging units of Alentejo Region: South Portugal (Maria \& Loureiro, 2014). 
According to the Raajpoot, Koh and Jackson (2010, as cited in Radder \& Han, 2015), the very nature and regardless of the types of collections that the museum hold, most museums provide opportunities for awareness and learning through offerings such as historical recreations, art exhibits, guided tours and audio guides interpreting the museum offerings.

Lee and Smith (2015) have delineated several learning importance of historical places by indicating that tourists visiting historic sites and museums are interested in learning about their cultural identity and participating in the activities associated with culture identity-seeking. Similarly, in Lin (2006) it has been revealed that a museum is often considered an important place for connecting the past and present, and for learning about historical people's culture and achievement.

\section{Esthetic experience in tourism and hospitality}

Among the $4 \mathrm{E}$ dimension of experiences, historical and heritage sites can be regarded as more esthetic in nature as the (Suntikul \& Jachna, 2015) finding from the research based on 700 tourists in Macao's historic center concluded that 25 sites among 31 possess the ranking of esthetic $>$ entertainment $>$ escapism $>$ education profile of perception of the experience value of the Historic Center as a whole. It has showed that esthetic experience is dominant than other experiences in historical heritage sites.

In another work, Breiby and Slatten (2015) have attempted to link the esthetic components of tourist experiences with six experiential qualities including scenery views and architecture, and the consumer interpretation with physical environments (sign, symbols and artifacts), along with other visual aspect such as viewing scenery from a sightseeing bus, walking in the mountains, etc.

\section{Escapism experience in tourism and hospitality}

It has been found from the participant of Mountaineering that it demands active engagement and involvement and as such, participants have the opportunity to experience escapism. As per Pomfret (2006), spatial separation from the home environment and overnight stays in the mountains further enhances the escapism benefits for mountaineer tourists. Similarly, other adventure activities such as riverrafting also constitute the elements of escapism as it allows rafters to imagine that they are in a different world (Arnould \& Price, 1993).

\section{Entertainment experience in tourism and hospitality}

Hospitality service providers such as resort hotel must focus on the entertainment aspect as it is an integral motivation of tourist as a hotel guest (Ali, Hussain \& Ragavan, 2014). As per the Manthiou, Lee, Tang and Chiang (2014), the examples of entertainment experience in tourism and hospitality context includes music concerts, and art festivals, etc. 


\section{Research Design and Methodology}

In the present research, the researcher was interested to design and administer it as a blend of exploratory research using depth participant interviews in an ethnographic dialectical approach. Moreover, this type of research strategy allows the searcher to explore and examine the cultures and societies that are fundamental part of the human experience and ethnographer as researcher is not typically detached or uninvolved observer (Murchison, 2010) as there remains a completely two-way discourse between the researcher and the subjects or participants of the inquiry. In the present study, ontological perspectives have been related to the identification and selection of different Nepalese indigenous tourism and hospitality experiences. In the epistemological grounds, the present researcher inquired from the words of established professionals and scholars of tourism and hospitality experiences regarding the prospect of creating memorable experience. To transform the present idea of research from the ontological and epistemological perspectives, the present researcher made this endeavor a more qualitative journey. For this, the present researcher crafted it on an ethnographic dialectical approach while establishing the discourses with the participants of the study. An ethnographic dialectic serves as a means of discovery of truth through examining and interrogating competing ideas, perspectives or arguments for developing a holistic understanding of a society, community, group or organization from an insider's perspectives, by living with members over an extended period of time (Spradley, 1979, 1980).

The aim of the research was to explore the prospects of creating memorable experience in Nepalese tourism and hospitality industry. Interview were conducted with the representative of Nepalese tourism and hospitality sector who have extensive experience in this field such as hospitality entrepreneur, tourism and hospitality advocacy expert, cultural and pilgrimage tourism expert, rural and wildlife tourism representative and visitor. Interview were semi-structured and the interview questionnaire consisted of three sections. The first section was concerned with present practices and potentiality for creating memorable experience, the second section was concerned with the strategic course of action required, the third and fourth section was concerned with major challenges and solutions required for the creation of memorable experience.

The content of the interviews was thematically analyzed using the conceptual framework, previous literature and with the research objectives for acquiring the responses made by the interviewees and for drawing the detailed descriptions about the Nepalese tourism and hospitality experience realms. The nature of the qualitative interview has allowed the researcher to interpret the answers of the interviewees, which is in compliance with the ontological stance of this study. Furthermore, this method of interviewing allowed the interviewer to pose follow-up questions, leading 
to certain topics being explored even further (Kvale, 1996, as cited in Bryman, 2012). The interviews were recorded ensuring the highest level of details and thereby it allows a more thorough examination of what the interviewees have said (Bryman, 2012). Additionally, recording the interviews also has helped to correct the potential limitations within the memories of the researcher and has allowed the researcher to concentrate on listening to what the interviewee says allowing the researcher to ask probing and follow up questions.

\section{Participant Information}

The first interview was carried out with the specialist of policy advocacy expert in tourism, the second with the hospitality entrepreneur, the third one with hospitality advocacy expert, the fourth one with the wildlife and rural tourism representative, the fifth one was with cultural tourism expert, finally the sixth one with visiting scholar of tourism background for Nepal.

The policy advocacy expert selected for this inquiry is key driving force of Nepal Tourism Board. The hospitality entrepreneur in this inquiry is the great leadership figure in Nepalese hospitality industry possessing uniquely brief of talent and experience enough to proclaim as an inspirational leader in this sector. This person has been playing a leading role in LSG Sky Chefs, Radisson Hotel, Hotel Yak and Yeti and the Everest Hotel of Kathmandu with unconventional approach to drive the hospitality industry. The hospitality advocacy expert in this inquiry is the professional leadership figure from the Hotel Association of Nepal. The wildlife and rural tourism representative in this inquiry is the owner of a resort in Chitwan with great deal of understanding regarding the wildlife and rural tourism activities of and around Chitwan National Park. The cultural tourism expert in this inquiry is a retired government official and was an ex-district magistrate officer in a number of districts of Nepal. This person also holds extensive research in the field of Nepalese culture and tradition along with his deep knowledge in Nepalese pilgrimages and tourism. This person is also the author of famous book published in Nepali language 'Tirtha Paryatan' which means Pilgrimage Tourism along with several other literatures. The last informant in this qualitative research is the visiting scholar from Scotland with his extensive experience of travelling wildlife zones and with special background in trekking and mountain expedition in Nepal. This person is also profound in doing research activities in the field of tourism.

\section{Locating The Study}

All interviews were conducted on the premises of the participants' workplaces as per their wishes so that they could comfortably respond to the questions raised. The first in-depth interview was held with policy advocacy expert of tourism sector which required two extended meetings and it took seven hours to complete the 
overall interview sessions. The second interview was conducted with the hospitality entrepreneur, again having two meetings in six and half an hour to complete it. The third interview was conducted with hospitality policy advocacy expert in one meetings which required three-hours of time engagement. The fourth interview was conducted with wildlife and rural tourism representative in one meeting with fourhour of long discussion in completing the interview sessions. The fifth interview was conducted with cultural tourism expert in two extended visits which took a six-hour of time engagement. Finally, the present researcher conducted the sixth interview with the visitor scholar having the same number of contact meetings in a four hour of conversation.

\section{Findings}

This study finds out the presence of experiences realm in Nepalese context identifying clearly the underlying patterns, potentialities to confirm and validate the major prospects for creating memorable experiences. The information explored from the qualitative interview with the experience economy realm have clearly depicted the pattern of experiential values in Nepalese tourism and hospitality sector which shows the possibility for creating memorable experience and the actions required for further design of such prospects. In an experience economy there is no room for commoditized and didactic activities rather people are in search of self-tailored experience where they want to immerse, entertain, escape and also learn new things which is mostly relevant for tourism and hospitality industry. To prove the above belief in Nepalese context, the present research has serve as the founding pillars with the thorough examination of Nepalese tourism and hospitality elements as an experiential aspect which can be produced as dazzling, memorable and unique products. The most significant and attractiveness such as historical sites, natural landscapes, heritages along with several of others authentic version of Nepal's identity such as the diverse cultures, the majestic grandeur of the sacred Himalayas and the "Shangri-La" mysticism which have lured visitors from all corners of the globe to visit Nepal had always been the major concern and important aspects of Nepalese tourism but to clearly identify its major determinants for experiential outcomes has been examined in this research from the noticeable confirmation gained from the interviews which is not only matched with the conceptual framework but also tally with assumption and findings of literature review.

\section{Present status and potentiality for creating memorable experience}

In all interviews, the participants were clear about the Nepalese present potentiality in experiential service offerings from tourism and hospitality context.

The ranges of raw materials such as nature, culture, religion, and so many things can be blended to develop different types of products to create unique experiences --Tourism Advocacy Expert 
These raw materials can truly serve as an "agrarian economy" in Nepal for creating experiential tourism and hospitality offering if they are customized according to the experience economy theory.

In Hotel Yak and Yeti, we can see the marvelous display of Nepalese artifacts, Nepalese style menu made of lokta paper, Nepalese linens such as Dhaka cloths, etc. Hotel Dwarika has extensively used the local products such as ceramics plates, tea-pots, made from Bhaktapur, trays made from wooden blocks, staff uniforms totally designed in Nepalese style which is mostly liked by the leisure group -- Hospitality Entrepreneur

Leisure travelers mostly like esthetic experience as esthetics dimensions refers to the customer's interpretation and indulgent of the physical environment such as ambient conditions; spatial layout and functionality; sign and symbols, and artifacts (Hosany \& Witham, 2010; Bitner, 1992). Thus, Nepalese hospitality institution are offering indigenous experience and it is also confirmed that it possesses rich and diverse sources of esthetic appealing experience as well.

Besides, previous research of Lobo (2010) in leisure tourism context approves that customers of leisure industries consume experience as they are mostly influenced by the ambience of the environment but if the experiences are unpleasant, there is every chance that the customer's interests wane and ultimately their patronage is lost. But, the Nepalese hospitality institutions are offering indigenous experience and also has been confirmed that it possesses rich and diverse sources of esthetic appealing experience to attract tourist with their uncompromising needs. Thus the current potentiality is high in this regards.

Our tradition, culture and geography has served as a backbone for sustaining the Nepalese hospitality and also due to its uniqueness it has turned into second home for many tourists who gets positive influence after visiting this country -- Hospitality Advocacy Expert

Above statement from Hospitality advocacy expert signifies that our core identity such as traditions, culture and geography served as hospitality services have unique experiences because the tourists have created memorable moments and they are also engaged and also have the intentions to revisit.

There is immense potentiality to facilitate and promote the religious and cultural tourism as well as pilgrimage tourism of Nepal in the form of selling religious and social experiences -- Cultural Tourism Expert

This statement possesses the strong suggestions to customize the current services as experiential offerings to take full benefits from it.

In a single destination (Chitwan) the tourist can completely immerse themselves in the wildlife experience and they can also feel the glimpses of rural activities of Tharu 
peoples to experience primitive and traditional style of their social life and to understand the tribal culture -- Wildlife and Rural Tourism Representative

It also confirms the presence of conglomerating experiences in Nepalese major tourism resources.

Nepalpossess numerous globally-recognized visitor attractions, ranging from naturebased icons such as Everest, world class heritage sites, monuments and pilgrimages, best trekking routes as well as unique and varied wildlife spots such as National parks and protected areas, there is a blend of experiences which are very much essential for the visitor's experiential consumption requirement and which are also quite impressive and encouraging to fulfill the varied quest of the visitors -- Visiting Scholar

These words from visiting scholar signifies to confirm that there are plenty of choices and alternatives for the visitor's community to fulfill their desires and likings as per their diverse experiential's requirements.

\section{Realms of an Experience in Nepalese Tourism and Hospitality}

There were references to the realms of experience in Nepalese tourism and hospitality as the findings and statements

The tour package of Nepal which we call golden triangle is completely different from rest of the world because just in 7-10 days, 3 diversities of experience can be gained which includes sightseeing of cultural heritages in Kathmandu, feeling of Himalayan ambience in Pokhara and wild-life experience of sub-tropical jungle in Chitwan -Tourism Advocacy Expert

Thus, it is confirmed that the recipients of the product package will have esthetic experience from the sightseeing of Nepalese cultural heritage and it has also layered the educational experience opportunities to them by providing new learning atmosphere for understanding Nepalese cultural phenomena, art and crafts, architectural attributes and also the local way of doing things. While visiting wildlife zones, the tourists will have the opportunity to make safari tour and it is completely engrossed and absorbed activity due to its escapist nature. After all, if the tourists or clients wish to have entertaining experience they also can have it in the destinations like Pokhara and other places. Hence, it is clearly confirmed that a single tour package has the widest diversity of experience and it also has confirmed with the "sweet spot" principle (four realms of experience) of experience economy theory of Pine and Gilmore (1998). It clearly denotes that the reasons for the successfulness of these type of product packages in Nepal are also due to its coercive nature and for creating compelling experiences rather than being simply functional products.

While revealing the prospects of Nepal in creating memorable experience for the tourists and hospitality clients, proper theming of cultural attributes could be 
more customized and are also vital for staging the experience. The clients could also gain mesmerizing experience through the proper theming of indigenous cultural attributes.

We used to organize 'Bhaktapur Night' a theme based program of creating the scenes of Bhaktapur inside the hotel premise or banquet of the hotel with artificial Bhaktapur gates highlighting the Newari culture and lifestyle activities, cultural program including Dhime dance and Mask dance, serving typical Newari foods to the guests to create the live Bhaktapur scenario and it was the whole evening program created in Soaltee Crowne plaza by the incentive groups staying in the hotel like personalities of Toyota Company and Nikon Company, etc. Such customers were actually looking for a unique experience that would transport them to another world. Customers had frequently used the terms "It felt like I was in a different place or time zone," "I completely escaped from reality during the program" -- Hospitality Entrepreneur

As per the participant, the realm of "education" as well as "entertainment" was mentioned by the guests who had taken part in such program as the program had offered educational forums for their customers by inviting traditional Newari inhabitants and Newari peoples so that they could communicate and learn new culture and lifestyles. And they were "passively observed" during the program and appreciated the program without affecting the occurrence. These activities also visualize the particular kind of response given to the growing needs of guests who are not satisfied with ordinary accommodation and they also need original, expressive and unique experiences.

The immense importance of Nepalese cultural and religious resources is not only helpful for general tourism activities, but also it has risen as an alternative type of tourism.

The intangible assets of Nepal such as festivals and celebration and its offering in the form of tourism product at present will also help to improve quality and tourist experience -- Cultural tourism expert

This strongly suggest to customize the current potential services into experiential offerings to take full benefits from it. Previous study based on the experience economy theory in the context of temple stays by Song, Lee, Park, Hwang and Reisinger (2014) also approve that religiously motivated travelers seeks new type of experience product by staying in temples as their mode of accommodation because it offers them wellness and spirituality with unique religious atmosphere.

Being important segment of tourism industry, festivals are also experiential products and services, and its entertaining aspect of experience such as amusing to watch, captivating performance, etc. and entertainment quality have the most significant influence on optimal experience, visitor's satisfaction and intention to return (Grunwell \& Inhuuck, 2008; Manthiou, Lee, Tang \& Chiang, 2014; Cole \& 
Chancellor, 2009). Thus, in the country like Nepal where hardly a day passes without a festival being celebrated somewhere; festivals, events and ceremonial performance also can be staged as an experience.

Tourists can entertain themselves in the cultural dance programme held by tharu residents, can learn about the primitive lifestyles of tharu peoples -- Wildlife and Rural Tourism Representative

There are lot of excitement inside the jungle of Chitwan national park as the tourists can watch amazing birds and mammals -- Wildlife and Rural Tourism Representative

Tourist are seen as loosing themselves in the jungle trek and they like the moments of sightseeing several endangered species and animals on the way to their safari tour -Wildlife and Rural Tourism Representative

Several tourists also take part in elephant bathing activities to enjoy the playfulness of elephant during its bath in the river -- Wildlife and Rural Tourism representative

The entertaining aspects of tourist moment in local cultural performances, watching and understanding about different bird, plant and animal's species, moments of losing themselves inside jungle wilderness and the tourist participation in elephant bath denotes enjoyable moments of both active and passive participation as well as absorption and immersion and all the realm of experience has been mentioned by the participant in above statements.

There are lot of enjoyable and beautiful sceneries captured in my mind which I had come across during my splendid trekking activities in several famous trekking trails of this country and the remembrance of those images remember me about this country -- Visiting Scholar

Overall satisfaction gained through Nepal's visit was remarkable with lot of exciting and never forgetting experiences such as pleasurable memories of beautiful sceneries, exciting trekking and time forgetting mountaineering activities -- Visiting Scholar

It shows that the esthetic appealing of Nepal's images and places has occupied the visitor mind and has also created unforgettable memories.

\section{Newer avenues and prospects for experience economy}

The interviews also showed new prospects which can definitely serve to create the settings for unique experience.

There can be a specific segment of tourism developed in Pashupatinath temple in Kathmandu of Nepal as several tourist flock to evening prayer program known as aarati ceremony on the bank of Bagmati River every day. They are attracted by the unique way of worship which is fascinating as music with mantras, kirtan, bells, insence, light, etc and its 
demonstration gives them heart-touching experience and they also participate actively in the celebration by clapping their hands at the sound of bhajans, ringing the bells to offer life-long gratitude to the Lord Shiva. Along with this esthetic experience tourist also communicate with local peoples and closely interact with them -- Cultural Tourism Expert

This shows that promotion of interdependence between tourism and other religious activities pursued by the resident human population and the tourist can be the key factor concerned. Nepal possess several unique cultural relics and as todays tourist are also more concerned with the traditional and local versions of product and services such as local way of doing things for their ultimate quest of experience.

As such, the creation of the themed set of attraction around temples and monuments could be more dynamic experiential offering to the tourist fulfilling their experience desire by signifying local authenticity. Nepal bears the potentiality in the form of vast variety of cultural resources and abilities to offer tourists in the form of art, cultural events, architecture and local dresses, handicrafts, languages, religions, traditions, art galleries, music, local cuisines, theaters, museums, special events, festivals, fairs, etc. Thus, the tourist may intend to experience all of them or may choose to participate in only one activity or event at a time. Taking these things in mind, the packages and product to offer could be innovated as substitutable cultural tourism experiences. So the role of entrepreneurs in this category is vast as they could investigate and develop the cultural dynamic experience products and services.

\section{Major challenges}

On the basis of several opinions suggested by the participants of this study, the following challenges were revealed for the success in creating experiences from Nepal's tourism and hospitality industry in the present context:

1. Lack of proper market segmentation to value prevailing system in order to have proper market linkages in tourism and hospitality context.

2. Few risk taking entrepreneurs to create and design new products in the market due to less support from other partners as well as from government.

3. Lack of proper advocacy to get appropriate protection from government side and no mechanism of co-ordination for handling sub-sector conflict in associated organization.

4. The predominant influence of chain operation and the influence of European food traditions and substantial commodified activities and the prevalence of traditional and primitive model of hospitality operation in Nepal.

5. Uncertain political and economic situation had stifled new investment opportunities and frequent natural disasters such as earthquake, landslide, flood, etc. had created adverse impact. 
6. The tourism industry is not getting priority in the investment as associated governmental, non-governmental and private investors are involved more on the promotional activities rather than in the development of infrastructures.

7. Lack of occupational skills and knowledge among tourism human resource in Nepal.

\section{Implications for strategic solutions}

On the basis of inputs provided by the various participants of this study and available information on world practices, the following strategic solutions were extracted to address the above mentioned challenges:

1. The provision of cash convertibles initiative and policy from the government to encourage the entrepreneurs for making more customer centric atmosphere and activities to innovate and design new forms of tourism in the place of traditional tourism also by including more innovative, specialized, customized and experience-oriented activities with Nepalese brand image.

2. Proper management of National flag carrier as well as strong committing government as an essential parameter for groaning Nepalese hospitality business.

3. Development of the qualified manpower through the proper training of employees involved in experience industries for the unfoldment of their efficiencies.

4. Development and promotion of experiential religious products by the invention of new ideas and the promotion of the religious products including souvenirs, decorative art, paintings, carvings and crafts through advertisements, national and international music extravaganzas and religious shows.

5. Presentation and preservation of the main types of religious spots found in Nepal in a natural state depicting their aesthetic beauty and religious purposes and rehabilitation and refurbishment of existing buildings and religious sites without tampering their intended original meaning.

6. The provision of educational and religious appreciation opportunities for the present tourism professionals.

7. Creating the loyalty among the visitors by creating pleasing environments, providing different forms of entertainments and plenty of excitement layered in the product packages by means of good marketing strategies and clear understanding of tourist's preferences as the country lacks modern technologies and skilled human resources. 


\section{Conclusions}

This study is resulted as the supportive evidences to prove that there are vast prospects for creating memorable experiences in Nepalese tourism and hospitality as there are abundance of education, entertainment, esthetic and escapism experience in Nepal's offering in the form of tourism and hospitality services. The results also showed that several satisfaction and emotions are associated with the experiences gained from these exceptional services. This study also examined what can be the future innovation and development for the hospitality and tourism product in experience economy concept by clearly understanding the challenges associated for strategically converting those challenges into an appropriate solution. The prominence and abundance of Nepal's experiential attributes in major tourism and hospitality elements has created the plenty of opportunities for selling experience layered in products, packages and services to the tourist, visitors and hospitality seekers when they visit this nation and when they intake these services. The evidences from the study has confirmed that the core activity of tourism and hospitality is about learning, entertaining, escapism and enjoying esthetic experiences and the findings from this study clearly confirms that almost every element of Nepalese tourism and hospitality entails some sorts of experience and by means of understanding those experiential attributes, it could be customized properly in order to stage them for acquiring more benefits both for the providers and consumers. More importantly, the findings have showed that the tourism experience in Nepal are also not relying totally on staging activities but also on less formal activities which encourage visitors to actively participate and personally create their experiences.

\section{Implications}

The present study contributes to the nascent body of research on the experience economy's application to tourism and hospitality experience in Nepal. The present research findings are equally useful for the strategic planning and policies formulation, marketing and institution-level decisions.

From the policy level, it is highly recommended that for the prosperity of tourism and hospitality business, proper policy measures should be developed in accordance with the creation of experience based tourism and hospitality infrastructure to facilitate and develop major attractions of Nepal's identity. There should be national policy and strategy on tourism and hospitality sector promotional communication so that the country can be promoted as a source country of number of tourism and hospitality services.

From the present study, the tourism and hospitality planners can identify the most significant area and priority to develop and promote the tourism and hospitality in terms of experience economy and disseminates it to the public sector, the cultural 
sector and to businesses providers with necessary guidance and advice to businesses that want to develop with experiences based tourism and hospitality products.

The marketers should clearly understand and evaluate the customer preference to innovate dynamic products and services. In the Nepalese context, the esthetic and educational dimension of experience prevailed as the strong dimension. This underscores the necessity of tourism and hospitality providers to pay keen attention to highlighting this dimension in their promotional activities and while designing products. Thus, the marketers should have particular resonance to these experiences.

The present study has demonstrated that the original experience economy instrument could successfully be adapted to measure the supply side of tourism. These results contribute to further refinement of experience economy theory in Nepal's tourism and hospitality experience consumption widening it to the practical possibility and probability for the experience creators and experience consumers. The practical implications of the contribution of this study has also expanded and there should be a series of research and innovation initiatives carried out keeping in view the main idea of the present study.

The result of this study have several theoretical implications. Firstly, the findings of the study prove that the experience economy theory is an appropriate conceptual framework for predicting Nepal's prospects for creating memorable experience in tourism and hospitality sector. Secondly, the creation of memorable experience requires different and unique products with appealing attributes, should have at least one or more realm of experience. Only renowned and luxurious property and fascinating services alone cannot enchant the customer because they also want to have good and lasting memories by collecting experiences. Thirdly, the hospitality and tourism market has expanded in recent times due to several competitions to attract and retain customers. In this scenario, developing customer centric and experience focused product and package can enhance the competitive position as well as distinctive brand image among the customers.

\section{Future Research Suggestions}

The limitation of this study also suggest for future research. For acquiring the generalization of this study each and every sector of tourism and hospitality industry is needed to be tested independently and separately thus it also awaits for further validation and attestation. Because of the qualitative nature of this study, the present research could not validate it from the perspective of descriptive analyses and statistical testing. So, there is a need for an exhaustive research based on experience design, experience innovation and experiential marketing. Thus, several present researches using mixed methods would serve the purpose. There is also a need for 
more exhaustive research based on experience design, experience innovation and experiential marketing. The marketers can also clearly understand and evaluate the customer preference to innovate dynamic products and services.

\section{References}

Ali, F., Hussain, K., \& Ragavan, N. A. (2014). Memorable customer experience: examining the effects of customer's experience on memories and loyalty in Malaysian resort hotels. Social and Behavioral Sciences, 144: 273-279.

Arnould, E. J., \& Price, L. L. (1993). River magic: extraordinary experience and the extended service encounter. Journal of Consumer Research, 20(1): 24-45.

Breiby, M. A., \& Slåtten, T. (2015). The effects of aesthetic experiential qualities on tourists positive emotions and loyalty: a case of a nature-based context in Norway. Journal of Quality Assurance in Hospitality \& Tourism, 16(4): 323-346.

Bryman, A. (2012). Social Research Methods. (4 ${ }^{\text {th }}$ Ed.). New York: Oxford University Press.

Cetin, G., \& Bilgihan, A. (2015): Components of cultural tourists' experiences in destinations. Current Issues in Tourism. doi: 10.1080/13683500.2014.994595.

Cetin, G., \& Istanbullu, F.I. (2014). Influence of customer experience on loyalty and word-of mouth in hospitality operations. Anatolia: An International Journal of Tourism and Hospitality Research, 25(2): 181-194.

Chang, S., \& Lin, R. (2015). Building a total customer experience model: applications for the travel experiences in Taiwan's creative life industry. Journal of Travel \& Tourism Marketing.

Ellis, G. D., \& Rossman, J. R. (2008). Creating value for participants through experience staging: Parks, recreation, and tourism in the experience industry. Journal of Park and Recreation Administration, 26 (4): 1-20.

Erdly, M., \& Kesterson-Townes, L. (2003). Experience rules: a scenario for the hospitality and leisure industry. Strategy \& Leadership, 31(3): 12-18.

Gelter, H. (2006). Towards an understanding of experiences production. Articles on experiences 4: Lapland Center of Expertise for The Experience Industry (LCEEI).

Getz, D. (2000). Explore wine tourism: Management, development and destinations. New York, Cognizant Communication Corporation.

Gilmore, J. H. \& Pine, B. (2002). Differentiating hospitality operations via experiences: Why selling services is not enough. Cornell Hotel and Restaurant Administration Quarterly, 43(3): 87-96. 
Hayes, D. \& Macleod, N. (2007). Packaging places: designing heritage trails using an experience economy perspective to maximize visitor engagement. Journal of Vacation Marketing, 13(1): 45-58.

Hemington, N. (2007). From service to experience: understanding and defining the hospitality business. The Service Industries Journal, 27(6): 747-755.

Hjalagr, A., \& Richards, G. (2002). Still undigested: Research issues in tourism and gastronomy. In A. Hjalager, \& G. Richards (Eds.), Tourism and Gastronomy. London: Routledge.

Hosany, S., \& Witham, M. (2010). Dimensions of cruisers' experiences, satisfaction, and intention to recommend. Journal of Travel Research, 49(3): 351-364.

Hwang, J., \& Lyu, S. O. (2015). The antecedents and consequences of well-being perception: an application of the experience economy to golf tournament tourists. Journal of Destination Marketing \& Management. http://dx.doi.org/ 10.1016/j. jdmm.2015.09.002.

Jensen, R. (1999). The dream society: How the coming shift from information to imagination will transform your business. New York, NY: Mcgraw-Hill.

Jurowski, C. (2009). An examination of the four realms of tourism experience theory. Available at: https://www.google.com.np/url?sa=t\&rct=j\&q=\&e $\mathrm{src}=\mathrm{s} \&$ sou $\mathrm{rce}=$ web $\& \mathrm{~cd}=1 \& \mathrm{cad}=\mathrm{rja} \& \mathrm{uact}=8 \& \mathrm{ved}=0$ ah UKEwiiqu_L_vJAhUJHI4KHaTwCfIQFggaMAA \&url= http\%3A\%2F\%2Fscholarworks.umass. edu\%2Fcgi\%2Fviewcontent.cgi\%3Farticle\%3D1054\%26context\%3Drefereed\&u sg=AFQjCNFYq8FsnkSXxSHsxyODU5xC6cQbaw\&sig2=nDz3apU07BV63lpr 4-EHwA

Kim, J. H., Ritchie, J. R. B. \& Mccormick, B. (2012). Development of a scale to measure memorable tourism experiences. Journal of Travel Research, 51(12): 12-25.

Knutson, B., Beck, J., Him, S. \& Cha, J. (2006). Identifying the dimensions of the experience construct. Journal of Hospitality \& Leisure Marketing, 15(3): 31-47.

Kunwar, R. R. (2011). Special interest tourism: a study of growing significance of food tourism. The Gaze Journal of Tourism and Hospitality, 3(1): 77-97.

Kvale, S. (2007). Doing Interviews. London: SAGE Publications Ltd.

Lamba, M. (2014). Nepal's tourism \& hospitality sector: A bird's eye view. Managing Director- The Hotels \& Hospitality Group of Jll. Available at: h t t p : / / w w w . joneslanglasalleblog.com/realestatecompass/real-estate/2014/08/nepalstourism-hospitality-sector-birds-eye-view/

Lee, H. M., \& Smith, S. L. J. (2015). A visitor experience scale: historic sites and museums. Journal of China Tourism Research, 11(3): 255-277. 
Lin, Y. N. (2006). Leisure - A function of museums? The Taiwan perspective. Museum Management and Curatorship, 21: 302-316.

Lo, A., Qu, H., \& Wetprasit, P. (2013). Realms of tourism spa experience: the case of mainland Chinese tourists. Journal of China Tourism Research, 9(4): 429-451.

Lobo, F. (2010). Consuming experiences: challenges for leisure and tourism. Loisir et Société / Society and Leisure, 33(2): 303-318.

Manthiou, A., Lee, S., Tang., L. \& Chiang, L. (2014). The experience economy approach to festival marketing: vivid memory and attendee loyalty. Journal of Services Marketing, 28(1): 22-35.

Maria, S. \& Loureiro, C. (2014). The role of the rural tourism experience economy in place attachment and behavioral intentions. International Journal of Hospitality Management, doi:10.1016/j.ijhm.2014.02.010.

Mehmetoglu, M., \& Engen, M. (2011). Pine and Gilmore's concept of experience economy and its dimensions: an empirical examination in tourism. Journal of Quality Assurance in Hospitality \& Tourism, 12(4): 237-255.

Mohsin, A., \& Lockyer, T. (2010). Customer perceptions of service quality in luxury hotels in New Delhi, India: an exploratory study. International Journal of Contemporary Hospitality Management, 22(2): 160-173.

Murchison, J. M., (2010). Ethnography essentials: designing, conducting, and presenting your research. New York: John Wiley \& Sons.

Oh, H. Fiore, A. M., \& Jeoung, M. (2007). Measuring experience economy concepts: Tourism applications. Journal of Travel Research, 46: 119-132.

Park, M., Oh, H., \& Park, J. (2010). Measuring the experience economy of film festival participants. International Journal of Tourism Sciences, 10(2): 35-54.

Pine, B., \& Gilmore, J. H. (1998). Welcome to the experience economy. Harvard Business Review, July-August, 97-105.

Pine, B., \& Gilmore, J. H. (1999). The experience economy. Boston, MA: Harvard Business School Press.

Pine, B. J. II., \& Gilmore. J. H. (1999). The experience economy: work is theatre and every business a stage. Boston: Harvard Business School Press.

Pomfret. G. (2006). Mountaineering adventure tourists: a conceptual framework for research. Tourism Management. 27(1): 113-123.

Pullman, M. E., \& Gross, M. A. (2003). Welcome to your experience: where you can check out anytime you'd like, but you can never leave. Journal of Business and Management, 9(3): 215-232. 
Quadri-Felitti, D., \& Fiore, A. M. (2012). Experience economy constructs as a framework for understanding wine tourism. Journal of Vacation Marketing, 18(1): 3-15.

Radder, L. \& Han, X, 2015). An examination of the museum experience based on Pine and Gilmore's experience economy realms. The Journal of Applied Business Research, 31(2): 455-470.

Rijal, C. P. (2015). Tourism as a frontier of experience economy in Nepal. Kathmandu: Author.

Roth, H., \& Fishbin, M. (2015). Global hospitality insight: Top thoughts for 2015. EY's Global Real Estate, Hospitality \& Construction Center.

Schmit, B. (2003). Customer experience management: A revolutionary approach to connecting with your customer. New Jersey: Wiley and Sons. Available At: http:// customerthink.com/customer_experience_management_a_revolutionary_ approach_to_Connecting_with_customers/

Siddharth Inc. (2015, July 24-30). Innovations in Nepal's Tourism Industry. Nepali Times. Available at: http://nepalitimes.com/page/innovations-in-nepal-tourismindustry.

Singh-Manhas, P., \& Singh, R. (2013). Customer experience and its relative influence on satisfaction and behavioural intention in hospitality and tourism industry. South Asian Journal of Tourism and Heritage. 6(1).

Song, H. J., Lee, C., Park, J. A., Hwang, Y. H., \& Reisinger, Y. (2014). The influence of tourist experience on perceived value and satisfaction with temple stays: the experience economy theory. Journal of Travel \& Tourism Marketing. doi: 10.1080/10548408.2014.898606.

Spradley, J. P. (1979). The ethnographic interview. New York: Holt, Rinehart \& Winston.

Spradley, J. P. (1980). Participant observation. New York: Holt, Rinehart \& Winston.

Sternberg, E., (1997). The iconography of the tourism experience. Annals of Tourism Research, 24 (4): 951-69.

Sthapit, E. (2013). Tourists' perceptions of memorable experiences: testing the memorable tourism scale (M.T.Es) among tourists to Rovaniemi. Lapland Pro Gradu Thesis Tourism Research, EMACIM Studies.

Suntikul, W., \& Jachna, T. (2015). Profiling the heritage experience in Macao's historic center. International Journal of Tourism Research. doi: 10.1002/jtr.2050.

Tarssanen, S. (2009). Handbook for experience stagers. (5 ${ }^{\text {th }}$ ed.). Rovaniemi. LEO, Lapland Center of Expertise for The Experience Industry. 
Tarssanen, S., \& Kylänen, M. (2006). A theoretical model for producing experiencesA Touristic perspective. Articles on Experiences 2. ( $3^{\text {rd }}$ ed.). Rovaniemi. Lapland Center of Expertise for The Experience Industry (LCEEI).

Toffler, A. (1980). The Third Wave. London: Collins.

Triantfillidou, A., \& Petala, Z. (2015). The role of sea-based adventure experiences in tourists' satisfaction and behavioral intentions. Journal of Travel \& Tourism Marketing. doi:10.1080/10548408.2015.1008667

Wang, Y., Feng, Y., \& Feng, B. (2013). The study on the significance of difference between demographics and tourist experiences in Macau casino hotels. Proceedings of 2013 International Symposium - International Marketing Science and Information Technology.

Willard, P., Frost, W. \& Lade, C. (2012). Battlefield tourism and the tourism experience: the case of Culloden. In: CAUTHE 2012: The new golden age of tourism and hospitality; Book 2. Proceedings of the $22^{\text {nd }}$ Annual Conference. Melbourne: La Trobe University, 2012: 665-670. 